\title{
Henrique de Beaurepaire Rohan Aragão
}

Mario B. Aragão* ～"Escola Nacional de Saúde Pública.

Em dezembro de 1979, a Fundaçao Oswaldo Cruz promoveu uma solenidade para comemorar o centenário de nascimento do Prof. Aragão, um dos fundadores, destacado pesquisador e, também, diretor do Instituto Oswaldo Cruz. Nessa oportunidade foi pronunciado, em nome da familia do homenageado, o discurso que os Cadernos estão publicando, como uma contribuiçao à história da Casa de Oswaldo Cruz.

Henrique de Beaurepaire Rohan Aragão. Do lado paterno estava representada a primeira civilização do Brasil, a civilização açucareira, o que talvez motivasse as suas posições políticas conservadoras, porém, sempre nacionalistas. Do lado materno, militares franceses dados às mais diversas manifestações intelectuais. $\mathrm{O}$ seu avô materno, já brasileiro, Marechal Henrique de Beaurepaire Rohan, considerado um dos fundadores da cartografia brasileira, governou províncias, construiu estradas e deixou um "Dicionário de Vocábulos Brasileiros", hå pouco reeditado, e que ainda é obra de consulta obrigatória por todos os lexicógrafos. Não é de espantar, portanto, que ojovem Henrique, ao necessitar fazer a sua tese de doutoramento, procurasse a velha fazenda de Manguinhos onde, tendo como berço uma fábrica de soro antipestoso, nascia a medicina experimental brasileira e, por que não dizer, também biologia. Não queremos ser injustos com os grandes botânicos do passado, com a Escola Tropicalista Baiana, nem com os homens do Museu Nacional. Acontece que, aqui em Manguinhos, diversos problemas sanitários que assolavam o país consolidaram a medicina experimental e orientaram a biologia brasileira para novos campos de estudo.

Essa escolha feita, também, por outros jovens de talento que desejavam desenvolver sua capacidade intelectual, é atribuída, com justiça, à personalidade de Oswaldo Cruz. Entretanto, algo mais devia existir. Lembro-me que, diversas vezes, o Prof. Aragão contou o que ocorria com um laboratório que um professor da Faculdade de Medicina havia montado para uso particular. Isso provocou a maior curiosidade entre os estudantes e ele, com outros colegas, ficava proximo à porta na hora do professor chegar para, no momento da entrada, ver, pelo menos de longe, um labora. tório. 
Aqui, entre cavalos, frascos, corantes e microscópios, o jovem Henrique Aragão devia sentir-se à vontade. $\mathrm{Na}$ viagem longa e complicada, a reclamação era pelo tempo perdido, porque cansaço não entrava em cogitação.

Manguinhos nos primeiros tempos, e também na fase áurea, era a retaguarda da Saúde Pública.

Vivemos no Intituto de Malariologia, criado por Mario Pinotti, para dar suporte às suas campanhas sanitárias e, por isso, entendemos por que os primeiros pesquisadores de Manguinhos se dedicavam a assuntos tão diversos.

Quando a campanha sanitária era retardada por algum problema ainda não resolvido, os pesquisadores eram chamados para estudar o assunto e indicar uma solução. Quando tudo estava correndo bem, podiam dar asas à imaginaçao e se dedicar à pesquisa básica. Nessa última atividade, se armavam cientificamente para os novos problemas que, certamente, viriam a surgir. $\dot{E}$, seguramente, nesse revezamento de tarefas que está a chave da eficiência e do alto nível científico e intelectual dos primeiros homens de Manguinhos.

Não é escolhendo um assunto porque ele é bem recebido em revistas estrangeiras que vamos ser úteis à coletividade e fazer avançar o conhecimento humano. Manguinhos foi grande quando procurou ser útil ao país e, eventualmente, chegou a ser útil a outras nações. Estão aí a doutrina domiciliar da malária, de Carlos Chagas, o tratamento das leishmanioses, de Gaspar Vianna, e o estudo do vírus do mixoma dos coelhos, de Henrique Aragão.

Se algum dia desejarmos repetir o fenômeno Manguinhos, teremos de entrosar a pesquisa com a saúde pública. A formação básica é indispensável; a chamada pesquisa desinteressada é importante para a satisfação intelectual, porém, quando não existir problema assolando o povo. Existe uma coisa que o Dr. Cynamon da Escola de Saúde Pública chama de "engenharia solidária", e é esse o grande desafio colocado diante dos pesquisadores. Em vez de pensar na obtenção do Prêmio Nobel, ou, às vezes pior, em levar uma vida cômoda, procurar reformar a mentalidade e se preocupar em ser solidário. Ainda mais, convencer-se de que é um empregado do povo que, na verdade, é quem paga o seu salário e as suas facilidades. É o que o Professor Aragão sempre repetia aos que não admitiam que o Instituto se envolvesse em assuntos não-científicos. Dizia ele: "É preciso não esquecer a função humanitária de Manguinhos".

A sua carreira científica se enquadra perfeitamente nesse esquema.

Veio para o Instituto, naquela época Instituto Soroterá. pico Federal, para aprender bacteriologia e fazer a sua tese. Logo em seguida se envolve com a peste que, em vez de estar como hoje no interior do Nordeste, freqüentava o 
Rio de Janeiro e o porto de Santos. Num acidente de labo. ratório, adquire a doença que deixou marca para toda a vida.

Pouco depois, num momento em que as tarefas premen. tes amainaram, resolve estudar um parasita do pombo. $\mathrm{O}$ motivo que alegava era ser um animal de fácil obtenção. Pois, dessa escolha, sai um dos grandes trabalhos do Instituto e num outro ramo de conhecimento, a protozoologia. É o ciclo evolutivo do hematozoário do pombo, que prece. deu de 30 anos a descoberta de ciclo semelhante encontrado na malária do homem.

Um problema da pecuária o leva a estudar os carrapatos, o que ele dizia fazer como subproduto de sua atividade científica. Entretanto, esse subproduto the foi muito útil no final da vida, pois permitiu que continuasse trabalhando até uma semana antes do seu falecimento. Nas Memórias do Instituto Oswaldo Cruz, do ano de 1956, estão os belíssimos trabalhos feitos em colaboração com o Dr. Flávio da Fonseca e publicados post-mortem. É necessário esclarecer que o Instituto tem duas importantes contribuições à pecuá. ria: a descoberta da vacina contra a manqueira e o controle biológico da praga dos coelhos na Austrália.

Tal como diversos homens de Manguinhos, também tra. balhou em profilaxia de malária e aqui perto, em São Bento, justamente onde, em 1949, foi instalado o Instituto de Malariologia, para cuja criação colaborou e que, depois de transferido para Belo Horizonte, passou a chamar-se Centro de Pesquisas René Rachou. Quero ressaltar aqui que nenhuma tạrefa, pọ mais rotineira que seja, diminui o pesquisador, pois Henrique Aragão foi distribuir cápsulas de quinino e mandar abrir vala em São Bento, depois de ter feito uma das descobertas mais fundamentais para o conhecimento dos plasmódios da malária, o já citado ciclo do hematozoário do pombo.

Depois de fundar a protozoologia no Instituto, onde fez um discípulo brilhante, Aristides Marques da Cunha, enveredou pela virologia onde, com seus trabalhos básicos sobre o vírus do mixoma dos coelhos, abriria um vasto campo tanto de aplicação prática, quanto de observação acadêmica. A epizootia de 1950, entre os coelhos da Austrália, foi o primeiro grande êxito de controle biológico por intermédio de microrganismo. Segundo o Prêmio Nobel Australiano Macfarlane Burnet, foi uma oportunidade única para "os epidemiologistas e que, nos anos seguintes, ele pôde acom. panhar, como se estivesse sentado numa poltrona de teatro, as modificações no vírus e na população de coelhos, que proporcionaram o equilibrio hospedeiro parasita.

É necessário destacar aqui a correção dos microbiologistas australianos que sempre mencionaram que a sugestão para esse trabalho e a remessa do vírus tinham sido feitas 
pelo Dr. Aragão. Cabe mencionar que deram contribuiçōes importantes ao problema Artur Moses, de Manguinhos, e Silvio Torres, do Instituto de Biologia Animal do Ministério da Agricultura, e que a grande massa de trabalho, do que se chama hoje de pesquisa e desenvolvimento, foi executada pelos cientistas australianos.

Um pouco depois, ocorre uma epidemia de leishmaniose tegumentar no bairro de Santa Teresa, aqui no Rio de Janeiro, e Aragão vai estudá-la. Faz interessantes observações epidemiológicas e consegue a transmissão experimental da Leishmania brasiliensis por um flebótomo, o que só recentemente foi repetido.

Continua suas pesquisas básicas, descreve um parasita de planta, faz conferências sobre endemas rurais, até que, em 1928, aparece a epidemia de febre amarela no Rio de Janeiro.

Aragão lança-se de corpo e alma ao estudo do vírus da febre amarela. Lembro-me que, nessa época, dormia dia sim dia não no Instituto. São desse período mais de uma dezena de trabalhos, alguns deles sobre a transmissão por intermédio do mosquito Aedes aegypti, em colaboração com o grande Costa Lima. Por fim, prepara uma vacina, a primeira ten. tada contra a febre amarela, e foi por esse motivo que o Ministro Mario Pinotti batizou o prédio onde é fabricada a vacina contra essa doença, de Pavilhão Henrique Aragão.

A descoberta da chamada febre amarela silvestre não deixou de despertar a sua atenção e, em 1937, foi chamado a dirigir o combate à febre amarela no Estado de São Paulo, ocasião em que organizou, pela primeira vez, no Brasil, uma estação biológica para estudo de mosquitos e outros animais da floresta.

Faz umas rápidas incursões na hidrofobia e, em seguida, é obrigado a substituir Cardoso Fontes na direção do Instituto. Nomeado diretor, a exemplo de seus antecessores, se afasta da pesquisa.

$\mathrm{Na}$ diretoria, a sua maior preocupaçao foi seguir as diretrizes traçadas por Oswaldo Cruz: servir ao país e manter o Instituto como uma instituição de vanguarda.

São desse periodo a criação da estação de biologia marinha, unidade pioneira no país, que desapareceu mas, em seu lugar, existem hoje instituições fortes como as de São Paulo, do Ceará c da Marinha de Guerra. O horto de plantas medicinais, espontaneamente, evoluiu para uma seção de estudo da vegetação. No Instituto ela terminou, mas foi frutificar no Projeto RADAM, onde o homem-chave do mapeamento da vegetação da Amazônia foi o Dr. Henrique Veloso, aposentado de Manguinhos.

Para lançar novamente o Instituto no interior do país, aproveitou alguns elementos que se tinham desenvolvido no Serviço de Estudo das Grandes Endemias, criado pelo 
extraordinário catalisador de talentos que foi Evandro

Chagas. Dessa forma nasceram os postos para estudo de esquistossomose em Pernambuco, de doença de Chagas em Bambuí, Minas Gerais, hoje Posto Emmanuel Dias, de onde partiu a profilaxia da doença por meio de inseticidas, e o de estudo da bouba, no Estado do Rio de Janeiro. Neste último, Nery Guimarães descobriu a cura da bouba pela penicilina e depois, em campanha realizada sob sua orientação, praticamente erradicou a doença do país.

Durante os anos da segunda grande guerra, igual ao que acontecia no resto do país, a parte industrial teve grande impulso. Dentre as fábricas instaladas, cabe destacar a de penicilina, que fornecia ampolas de 300 unidades, muito mais eficientes do que os milhões de hoje. Com essas ampolas de 300 unidades é que Nery Guimarães estudou o tratamento e conseguiu a cura da bouba. Deve-se esclarecer que, nessa época, o Instituto dispunha de uma poderosa divisão de química, criada na administração Carlos Chagas, e de diversos micologistas.

Por questões que não adianta nada relembrar, deixou a diretoria em 1949, vindo a cair na compulsória em 1950.

Logo em seguida, o Instituto entrou numa fase de agitação que também não vale a pena comentar, até que, a pedido do Ministro Miguel Couto Filho, Aragão indicou para diretor o Dr. Francisco Laranja, seu amigo íntimo e que foi, sem dúvida nenhuma, o melhor diretor que a instituição já teve, depois da fase dos fundadores.

Depois de cair na compulsória, voltou a trabalhar na sistemática dos ixodídeos, o que não exige esforço físico mas requer uma boa dose de experiência. Entretanto, a sua contribuição não ficou apenas nisso. Era um entusiasta das campanhas sanitárias desenvolvidas, nessa época, pelo Serviço Nacional de Malária e depois pelo Departamento Nacional de Endemias Rurais, e dava assessoria ao Dr. Mario Pinotti unicamente por amizade e vontade de ser útil.

Não alcançou a fase de relativo florescimento de Manguinhos sob a direção do Prof. Amilcar Vianna Martins e, felizmente, não assistiu aos diversos massacres que, posteriormente, viriam a ocorrer.

Ainda na semana em que faleceu, me pediu que viesse aqui explicar para o desenhista qual o carrapato que deve. ria ser desenhado. Em poucas palavras, continuava a seguir uma das máximas de Oswaldo Cruz e que sempre relembrava: "Não há nada que resista ao trabalho". 